\title{
4. Actor-network theory and the empirical critique of environmental law: unpacking the bioprospecting debates
}

\author{
Emilie Cloatre
}

\section{INTRODUCTION}

In this chapter, I interrogate how actor-network theory (ANT) can be used by environmental law scholars. The increasing enthusiasm for this approach in socio-legal circles will have rendered it familiar to many readers. ${ }^{1}$ If ANT's attention to materiality has become one of its bestknown features, this chapter interrogates its broader contributions, both conceptually, and as methodology. For environmental lawyers, two key points of interest emerge in particular from ANT: first, the approach has carefully challenged the nature/culture dichotomy, providing new ways to think the environment as social being; second, its heavy reliance on ethnography has the potential to open particular perspectives that environmental law has not always been receptive too. Both elements open broad questions about the object of environmental law, but also about the role of ethnography in scholarly research more generally (and in this chapter, I am particularly interested in its implications for critical analysis).

In order to illustrate its purpose, this chapter focuses on a specific example, to examine how an ANT-approach may emphasise particular features of environmental law: that of the ways in which bioprospecting has been regulated in environmental law since it emerged as a site of controversy in the early 1990s. Particular attention will be paid to one of the key materials that has emerged from these solutions: benefit-sharing contracts. The chapter will explore how the close unpacking of benefitsharing contracts, through the ethnographic details that anthropologists

1 Bruno Latour, We Have Never Been Modern (Cambridge MA: Harvard University Press, 1993); Bruno Latour, Reassembling the Social: An Introduction to Actor-Network Theory (Oxford: Oxford University Press, 2005); Bruno Latour, La Fabrique du Droit: une ethnographie du Conseil d'Etat (Paris: La Decouverte, 2004); Bruno Latour, Enquete sur les Modes d'Existence: une Anthropologie des Modernes (Paris: La Decouverte, 2012); Bruno Latour, Politiques de la Nature: comment faire entrer les sciences en democratie (Paris: La Decouverte, 1999). 
have provided of these, and through the conceptual tools provided by ANT, can participate in problematising the field in ways that more doctrinal environmental law has failed to do. In turn, this opens questions as to the possibility for law itself to solve the complex ethical concerns of the field through 'legal fixes' that continue to rest on categorisations that fail to seize the messiness of the social world that ANT insists on, and in turn continue to carry the script of the global inequalities that it seeks to challenge.

I start the chapter by briefly introducing some of the tenets of ANT. I then turn to illustrating the importance of such moves for environmental law by looking at the contrasting ways in which a particular environmental law problem, bioprospecting, and a particular legal answer to this problem, benefit-sharing contracts, have been explored both in environmental law, and anthropological analysis. In turn, the chapter reflects on how the complexity highlighted by empirical critiques can be effectively engaged by methodologies that seek to illustrate messiness rather than neat social categories, embeddedness rather than distinction, and entanglement rather than independent movements.

\section{ANT, FROM SCIENCE AND TECHNOLOGY STUDIES TO INTERDISCIPLINARY STUDIES OF LAW}

ANT emerged in the 1970s, as one of the key strands of thoughts of Science and Technology Studies (STS), as the discipline came to be established. It was born from the writings of now well-known scholars such as Michel Callon, ${ }^{2}$ Bruno Latour, ${ }^{3}$ John Law $^{4}$ or Anne-Marie Mol. ${ }^{5}$ While drawing on a variety of methodological and

2 Michel Callon, 'Some Elements of a Sociology of Translation: Domestication of the Scallops and the Fishermen of St Brieuc Bay', in John Law (ed.), Power, Action and Belief: A New Sociology of Knowledge? (London: Routledge, 1986a, pp. 196-223); Michel Callon, 'The Sociology of an Actor-network: The Case of the Electric Car', in Michel Callon, John Law and Arie Rip (eds), Mapping the Dynamics of Science and Technology (London: Macmillan Press, 1986b, pp. 19-35).

3 Latour 1993 supra n.1; Latour 1999 supra n.1.

4 John Law, 'On the Methods of Long Distance Control: Vessels, Navigation, and the Portuguese Route to India', in John Law (ed.), Power, Action and Belief: A New Sociology of Knowledge? Sociological Review Monograph 32 (Henley: Routledge, 1986, pp. 234-263); John Law, After Methods: Mess in Social Science Research, Making a Mess with Methods (London: Routledge, 2004).

5 Anne-Marie Mol, The Body Multiple: Ontology in Medical Practice (Durham: Duke University Press, 2002). 
theoretical ideas from philosophy and social sciences (including, notably, ethnomethodology), ${ }^{6}$ ANT's claim was to propose a radical shift in the way social relations were to be imagined. This shift can be summed up through a number of key concepts, in particular those of fluidity, entanglement and heterogeneity. For ANT, society is not a fixed entity that can be seized and described by its observers, and the social is not a predefined set of movements that can be used as explanatory categories of other phenomena. Instead, social relations are defined by their dynamic and fluid nature, in which any interaction between actors, or between events, reshape these very actors as they produce new movements and new happenings. In turn, this means that any particular object of inquiry needs to be understood through the many events, the many interactions and the various meanings that construct it. It also means that as matters are being displaced, categorised, ordered, they get transformed and re-emerge in new forms, and as new 'things'. ${ }^{7}$ This emphasis on fluidity and entanglement is born out particularly from, and has specific implications for, understandings of materiality for social scientists. One of the key claims of ANT, and possibly the one it has become most strongly associated with, is that the classic sociological divides between humans and nonhumans, and between nature and society, are themselves constructions of modernity, that bear little relationship to the actual nature of the world. ${ }^{8}$ If everything is entangled and indeterminate, then materials themselves become complex, enabling (or not), powerful, and 'part' of humans as much as humanity is part of the things it produces, is born out of and experiences. While shortcuts into ANT can suggest that this emphasis on the importance of 'things' is its key contribution, and while much scholarly work that has turned to ANT has done so because of a particular interest in materials, or a particular set of materials, it is essential to keep in mind that this effort to bring things back into social analysis is itself only the consequence of a much broader point made by ANT: that nothing, not even materials that look relatively simple, and relatively fixed, are to be taken for granted, or seen as truly stable. Social relations are heterogeneous, messy, easily unsettled, and the role of social critique becomes to remind us of this messiness, even as practices of ordering (including through law) often continue to rest on much more structured imaginaries of the world.

Harold Garfinkel, Studies in Ethnomethodology (London: Wiley, 1984).

7 The overlaps with the ideas of Karen Barad, for example, are visible here; Karen Barad, Meeting the Universe Halfway: Quantum Physics and the Entanglement of Matter and Meaning (Durham: Duke University Press, 2007).

8 Latour 1993 supra n.1. 
These different ideas are of significance for legal studies. ${ }^{9}$ Law, through the conceptual lens offered by ANT, becomes co-productive of this heterogeneous and messy social materiality. In turn, its boundaries are more fluid, uncertain and easily unsettled than those it sets or draws for itself, and we need to reimagine the law as more socially contingent than a fixed system of rules. It is worth pointing out, however, that both understandings of these boundaries, and of the particularities of law as social domain, vary to some extent within relevant scholarship. Notably, different scholars relying on some of ANT's ideas have contrasting understandings of the particularities of what Latour would refer to as law's modes of existence. ${ }^{10}$ To some extent, these contrasting positions also reflect disciplinary and methodological underpinnings, and a contrast for example with more philosophy-oriented or ethnography-inspired positionings. This is a point worth keeping in mind for example for readers seeking to understand how Latour's relatively recent explicit engagement with law may relate to earlier 'law and ANT' scholarship, and indeed for readers who want to conceive of the nature of law, its social modes of action, and its fluid boundaries.

In this chapter, I remain primarily grounded in ANT writings that rely on thick ethnographies of the everyday to rethink the complexity of the social, rather than on more recent philosophical engagements with Latour's explorations of law. This is both because of my general concern for the importance of seizing the micro-processes that animate the daily lives of law, and because this type of analysis remains too rare in environmental law, and therefore has a lot to contribute. ${ }^{11}$ If focusing on this anthropological strand within ANT as a starting point for the analysis of law, and of environmental law in particular, two key contributions can be made: first, the methodological implications suggest a return to an ethnographic attention to the day-to-day of law, its localised making, unmaking, settling and challenging. At the same time, at the conceptual level, these approaches, suggest a more radical dissolution of the stability of law as

9 Emilie Cloatre, Pills for the Poorest: An Exploration of TRIPS and Access to Medication in Sub-Saharan Africa (Houndmills: Palgrave Macmillan, 2013); Ron Levi and Mariana Valverde, 'Studying Law by Association: Latour goes to the Conseil d'Etat', 2008 Law and Social Inquiry 3, 805-825.

10 Latour 2004 and 2012, supra n.1; Valverde and Levi, supra n.9; Frederic Audren and Cedric Moreau de Bellaing, 'Bruno Latour's Legal Anthropology', in B. Banakar and M Travers (eds), An Introduction to Law and Social Theory (London: Hart, 2013, pp. 181-195).

11 Cloatre (2013) supra n.9. 
a defined social field, whose existence is at any point a given and independent source of norms, seeing in its place a field always in the making, and inherently entangled in other forms of social making and unmaking. The boundaries between law and society, legality and illegality, regulated and unregulated spaces, law on paper and law in action, that have been accepted and built upon in much legal scholarship, similarly start dissolving once legal processes become analysed in terms of their material making and entanglements. I return later in this chapter to the broader question ANT-inflected approaches raise for the relation between ethnography and critique, but before doing so I turn to the example of bioprospecting as a way to examine what an ANT approach to environmental law may entail.

\section{ENVIRONMENTAL LAW, ANT AND THE IMPORTANCE OF ETHNOGRAPHIC COMPLEXITIES: UNPACKING BIOPROSPECTING}

This section turns to the well-known debate in environmental law over 'biopiracy', or the ethically dubious aspects of the practice of bioprospecting. ${ }^{12}$ It starts by introducing the issue, before turning to the answers provided by environmental law, and the various questions that their analysis as a 'messy answer to a messy problem' can contribute to the field, through the concepts of ANT and some of the empirical details that several anthropologists have offered - but that have remained absent from much environmental law scholarship on the topic. Bringing together questions of intellectual property, access to natural resources, rights over nature and knowledge, and raising issues that cut across space and time, the problem is a multi-layered one that seems to evade straightforward solutions - and indeed constitutes a useful illustration of a series of what Anna Tsing refers to as sites of 'friction'. 13

\footnotetext{
12 For an introduction to the issue see for example Daniel F. Robinson, 'Locating Biopiracy: Geographically and Culturally Situated Knowledges', 2010 Environment and Planning A 42(1), 38-56; Katie Moran, Steven King and Thomas Carlson 'Biodiversity Prospecting: Lessons and Prospects', 2001 Annual Review of Anthropology 30, 505-526. See also: Emilie Cloatre, 'Biodiversity, knowledge and the making of rights: reviewing the debates on bioprospecting and ownership', in M.J. Bowman, P.G.G. Davies and E.J. Goodwin (eds), Research Handbook on Biodiversity \& Law (Cheltenham: Edward Elgar, 2016).

13 Anna Tsing, Friction: An Ethnography of Global Connection (Princeton, NJ: Princeton University Press, 2005).
} 


\section{The Ethical and Political Making of Bioprospecting}

Bioprospecting can be defined as the systematic search for biological resources by researchers in the life sciences (notably the pharmaceutical field), with a view to facilitating future advancements in research and innovation. Often this search is guided, or aided, by the knowledge that local people, communities, healers or farmers have developed around particular resources. Given the entanglement of the various forms of knowledge, enterprises, cultures and power dynamics that such searches and exchanges may entail, it is no surprise that controversies and tensions have emerged around some of the strategies involved..$^{14}$

The use of natural resources and associated traditional knowledge for industrial purposes has a long history, dating back to the early days of colonialism, ${ }^{15}$ with notable products such as quinine being based on discoveries dating from these times. ${ }^{16}$ If empires facilitated the extraction of both plants and knowledge from local populations, bioprospecting as a process has continued well beyond the colonial era and to this day. With time, it has been transformed into a systematic and organised practice of collection, ${ }^{17}$ the future of which is partly challenged by a greater turn of the pharmaceutical industry towards synthetic chemistry, ${ }^{18}$

14 For context see I. Mgbeoji, Global Biopiracy: Patents, Plants and Indigenous Knowledge (New York: Cornell University Press, 2006); Robinson 2010 supra n.12; Moran, King and Carlson 2001 supra n.12; Graham Dutfield, 'Sharing the Benefits of Biodiversity: Is There a Role for the Patent System?', 2002 Journal of World Intellectual Property 5(6), 899-931.

15 Londa Schiebinger, Plants and Empire: Colonial Bioprospecting in the Atlantic World (Cambridge MA: Harvard University Press, 2004); Abena Osseo-Asare 'Bioprospecting and Resistance: Transforming Poisoned Arrows into Strophantin Pills in Colonial Gold Coast, 1885-1922', 2008 Social Science and Medicine 21(2), 269-290.

16 Cori Hayden, When Nature Goes Public: The Making and Unmaking of Bioprospecting in Mexico (Princeton, NJ: Princeton University Press 2003b); C. Hayden, 'From Market to Market: Bioprospecting's Idioms of Inclusion', 2003a American Ethnologist 30(3), 359-371; Michael J. Balick and Paul Alan Cocks, Plants, People and Culture: The Science of Ethnobotany (New York: Scientific American Library, 1996).

17 Shane Green, 'Indigenous People Incorporated? Culture as Politics, Culture as Property in Pharmaceutical Bioprospecting', 2004 Current Anthropology 45(2), 211-237.

18 Anthony Artuso, 'Capturing the Chemical Value of Biodiversity: Economic Perspectives and Policy Prescriptions', in F. Grifo and J Rosenthal (eds), Biodiversity and Human Health (Washington, DC: Island Press, 1997, pp. 184-204); Bruce Aylward, 'The Role of Plant Screening and Plant Supply in Biodiversity Conservation, Drug Development, and Health Care', in T. Swanson (ed.), 
but that is expected to continue in some form in the foreseeable future. ${ }^{19}$

Since the 1990s, and as it continued to persist and become visible or reported in new ways, the ethical challenges bioprospecting raises have also become visible. Since then, critical scholarship has sought to interrogate the meaning of these practices for understanding the positionality of nature in processes of globalisation, and of the interrelationship between knowledge, culture and (relative) power. ${ }^{20}$ At the same time, movements of social resistance have grown across the world, in response to particular missions, or particular patents. ${ }^{21}$ For ANT scholars, such moments of controversy help render visible the political nature of knowledge processes and generate the interessement of new actors, themselves ready to transform the particular processes at stake. ${ }^{22}$ As resistance gathered, bioprospecting became settled as a new field for ethics, and for law, to engage with. It also became a field characterised by its global implications. Well beyond its colonial origins, bioprospecting continued to operate along a broadlydrawn 'north/south' divide. This is both due to the rich biodiversity of many southern nations, ${ }^{23}$ and to the persistence of relations of global inequality beyond the colonial era that characterises contemporary science. $^{24,25}$

In terms of their focus, much of the tensions around bioprospecting

Intellectual Property Rights and Biodiversity Conservation (Cambridge: Cambridge University Press, 1995, pp.93-126).

19 E.g. Erik J. Buenz et al., 'Searching Historical Texts for Potential New Drugs', 2006 British Medical Journal 333, 1314-1315.

20 Rosemary Coombe, The Cultural Life of Intellectual Properties: Authorship, Appropriation and the Law (Durham, NC: Duke University Press, 1998); Rosemary Coombe, 'Legal Claims to Culture in and Against the Market: Neoliberalism and the Global Proliferation of Meaningful Difference', 2005 Law, Culture and the Humanities 1(1), 35-52; Hayden 2003a supra n.16; Hayden, C. 2003b supra n.16; Alain Pottage, 'Too Much Ownership: Bioprospecting in the Age of Synthetic Biology', 2006 Biosocieties 1(2), 137-159; Marcia Ellen DeGeer, 'Biopiracy: The Appropriation of Indigenous Peoples' Cultural Knowledge', 2003 New England Journal of International and Comparative Law 9, 179-208.

${ }_{21}$ Vandana Shiva, Biopiracy: The Plunder of Nature and Knowledge (Boston: South End Press, 1997); Robinson 2010 supra n.12; DeGeer 2003 supra n.20; Mgbeoji 2006 supra n.14.

22 Callon 1986a and b supra n.2.

23 Shiva 1997 supra n.21.

24 Laurelyn Whitt, Science, Colonialism, and Indigenous People: The Cultural Politics of Law and Knowledge (Cambridge: Cambridge University Press, 2009).

25 E.g. Hayden 2003b supra n.16. 
have centred on questions of ownership, and in turn on how we should conceive of the relative contribution of various actors to the making of new products, and new knowledge. This has materialised mostly around patents, as a particular form of ownership and of reward. Patents operate a key role in bioprospecting activities, as the ultimate aim of such mission (achieved in a very small portion of cases) is to produce a new product that can be used industrially, and be sufficiently novel and inventive to attract potentially very lucrative patent rights. ${ }^{26}$ Of course, neither the questions of novelty nor inventiveness are straightforward, either in socioethical or even purely legal terms, and in contexts where knowledge is exchanged, borrowed and translated as many times as it is in the context of bioprospecting, this is particularly so. Throughout the debates, the place of law in bioprospecting has been, at the same time, that of an actor of (dis)possession, of a key trigger in the constitution of a resistant network, and of a potential source of solution to ongoing conflicts.

At the very core of the tensions created by bioprospecting are contested perceptions of the value of knowledge, and of 'valuable knowledge'. ${ }^{27}$ Plants collected through bioprospecting find themselves at the crossroad between competing knowledge-systems. On the one hand, experiential, long-discovered, broadly practised and often shared forms of knowledge over plants constitute one of the starting points of the final assemblage provided. These come to researchers with the appearance of localised routes (though the nature of that 'locality' itself is uncertain, as developed below), and are often deeply embedded in broader socio-political messiness - including that of so-called traditional (or revisited) medicines. On the other hand, once collected by researchers, plants become open to and opened by a very different knowledge-system, based on experiments, on scientific logics, entangled in labs and industrial expectations, and with the potentiality of marketisation. The links and transitions between these two systems, and the related translation of plants from one set of actors into another, is itself mediated in ways that vary in almost each bioprospecting mission, which, as we will see below, complicates any conversation about whose knowledge is being passed on or built upon.

\footnotetext{
26 Mgbeoji 2006 supra n.14; Shiva 1997 supra n.21.

27 Itself a complex process entangled in other forms of social inequalities, as much STS scholarship has demonstrated (e.g. Sandra Harding, The Postcolonial Science and Technology Reader (Durham: Duke University Press, 2011); Sandra Harding, Sciences from Below: Feminisms, Postcolonialisms and Modernities (Durham: Duke University Press, 2008); Warwick Anderson, 'Postcolonial Science Studies', in N. Smelser, J. Wright and P. Baltes (eds), International Encyclopedia of the Social and Behavioral Sciences (Palo Alto and Berlin: Elsevier, 2005, pp. 652-657).
} 
As a whole, these different elements place bioprospecting at the interface of a series of complex debates: on the position of nature in scientific development (and indeed on the conceptual possibility of isolating 'nature' from its industrial ramifications in such debates); on the relative value of contrasting forms of knowledge and knowledge-systems, and consequently of the different cultural underpinning that they co-produce; in turn, on the ways in which such valuing may result from and produce persisting social inequalities; on the ethics of ownership, of intellectual property law, and of the underlying systems of rewards that come to constitute neoliberal relations. The complexity of these debates illustrates starkly ANT's critique of the nature/society divide. Here, plant resources are decidedly hybrid, and their actors are unclear and contested..$^{28}$ This complexity and the fluid shapes of the actors involved have made any attempts at a legal response particularly difficult, opening new questions with each answer provided.

\section{FROM INTERNATIONAL AGREEMENTS TO CONTRACTUAL SHARING OF BENEFITS}

Conversations on the possible role of law in solving these issues have travelled across numerous foras, reflecting the entanglement of each aspect of the debate in, for example, conversations on biotechnology, agriculture, ownership, cultural rights and biodiversity. However, the most detailed legal framework developed to respond to the debates flows from the Convention on Biodiversity (CBD) and its 2010 Nagoya Protocol. My aim here is not to provide a detailed analysis of these instruments - and indeed much legal analysis of these has already been produced ${ }^{29}$ - but instead to interrogate how these texts and the solutions proposed are translated into localised practices, and how this translation can be approached.

While many agree that the CBD demonstrated a discursive shift in the way natural resources were approached at the international level, its

\footnotetext{
28 Hayden, 2003b supra n.16; Pottage 2006 supra n.20.

29 Catherine Aubertin and Geoffroy Filoche, 'The Nagoya Protocol on the Use of Genetic Resources: One Embodiment of an Endless Discussion', 2011 Sustentabilidade em Debate - Brasília 2(1), 51-64; Evanson Chege Kamau, Bevis Fedder and Gerd Winter, 'Nagoya Protocol on Access to Genetic Resources and Benefit-Sharing: What is New and What are the Implications for Provider and User Countries and for the Scientific Community?' 2010 Law, Environment and Development Journal 6(3), 248-262; Kabir Bavikatte and Daniel F. Robinson, 'Towards a People's History of the Law: Biocultural Jurisprudence and the Nagoya Protocol on Access and Benefit-Sharing', 2011 Law, Environment and Development Journal 7(1), 35-50.
} 
practical impact has been more contested. Indeed, at one level, the CBD challenges the nature/culture divide by recognizing the tight relationship between people and resources. At the same time, its contributions remain constrained in at least two ways: first by the difficulties of translating such a broad international statement into any meaningful everyday problematisation; second by the maintenance of potentially conflicting, and more powerful legal instruments, including in intellectual property. ${ }^{30}$

The next section focuses on the former point, to demonstrate the importance of following the everyday traces of the CBD in its materialised practice, in order to understand its meaning and the multiple levels of translation that surround such a document. The translation of the principle of benefit-sharing from the text of the CBD and the Nagoya Protocol into the daily practices of those concerned, has been mostly effected and materialised through the use of benefit-sharing agreements. These offer a particularly useful site both because of the complexity of their practical mechanics, and the expression of their hybridity as legal assemblages when practised, but also because of the richness of the few ethnographies of their day-to-day that have been produced by anthropologists of science. The chapter will then turn to discussing the entanglement of the CBD within broader international processes and politics, before returning to arguing for the importance of reflexive, multi-level ethnographies, such as those enabled by ANT, to understand environmental law better.

\section{THE COMPLEX PRACTICE OF BENEFIT-SHARING CONTRACTS: ORDERING NATURE/SOCIETY MESSINESS}

Benefit-sharing agreements have proven a fascinating site of ethnographic exploration. ${ }^{31}$ Interestingly, environmental law scholarship has paid relatively little attention to such rich anthropological studies, even as they acquired significant recognition in related disciplines, such as STS or anthropology of science. As an example, the widely-cited work of Cori

\footnotetext{
30 Graham Dutfield, Intellectual Property Rights, Trade and Biodiversity (London: Earthscan, 2000).

31 For example Hayden 2003a and 2003b supra n.16; A. Osseo-Asare, Bitter Roots: The Search for Healing Plants in Africa (Chicago: Chicago Press Books, 2014); Stephen B. Brush 'Bioprospecting the Public Domain', 1999 Cultural Anthropology 14(4), 535-555; Shane Green, 'Indigenous People Incorporated? Culture as Politics, Culture as Property in Pharmaceutical Bioprospecting', 2004 Current Anthropology 45(2), 211-237.
} 
Hayden on the INBio benefit-sharing contracts in Mexico, ${ }^{32}$ while broadly recognised and engaged in anthropology and STS, is seldom referenced in mainstream environmental law scholarship, even when the analysis proposed seeks to assess benefit-sharing contracts. ${ }^{33}$ The lack of attention of environmental lawyers to the micro-workings of benefit-sharing contracts raises interesting methodological questions for the field itself: to what extent can claims on law be made without some engagement with its daily practices? The questions at stake here are really both questions of implementation and questions about the boundaries of law, and where the role of the legal scholar should stop. Actor-network theory, following the tradition of anthropological questioning, suggests that the constituent parts of any object of study need to be followed through their minute workings, and relocated in their broader entanglements, in order for the overall picture not to be tainted by misconceptions. ${ }^{34}$ In this continuous search for details, complexity should unravel rather than become reduced. Indeed, those who have followed closely benefit-sharing contracts have suggested that their workings demonstrate the complexity of what these legal tools both embed and generate.

Benefit-sharing contracts are complex legal objects, even in their purely formal make-up: to sum them up, they are multi-party agreements between

32 Cori Hayden, 'Bioprospecting's Representational Dilemma', 2005 Science as Culture 14(2), 185-200; Cori Hayden, 'Taking as Giving: Bioscience, Exchange, and the Rise of an Ethic of Benefit-sharing', 2007 Social Studies of Science 5, 729-75; Hayden 2003a supra n.16.

33 As examples: Carmen Richerzhagen Protecting Biological Diversity (London: Routledge, 2010); James S. Miller, 'Impact of the Convention on Biological Diversity: The Lessons of Ten Years of Experience with Models for Equitable Sharing of Benefits', in C. McManis (ed), Biodiversity and the Law: Intellectual Property, Biodiversity and Traditional Knowledge (London: Routledge, 2007); S. Bhatti et al. (eds), Contracting for ABS: The Legal and Scientific Implications of Bioprospecting Contracts, IUCN Envtl Policy \& Law Paper No 67/4, online at <https://www.cbd.int/doc/books/2009/B-03183.pdf>; PIIPA (Public Interest Intellectual Property Advisors), Bioprospecting Resource Guide (2013), available at $<$ http://www.piipa.org/images/PDFs/PIIPA_Bioprospecting_Resource_Guide_20 13_Final.pdf>; C. Chiarolla et al., Biodiversity Conservation: How Can the Regime of Bioprospecting under the Nagoya Protocol Make a Difference?, IIDRI Studies No.06/13, available at <http://www.iddri.org/Publications/Collections/Analyses/Stu dy0613_CC\%20RL\%20RP_bioprospecting.pdf>; Elisa Morguera, Matthias Buck and Elsa Tsioumani (eds) The 2010 Nagoya Protocol on Access and Benefit-sharing in Perspective: Implications for International Law and Implementation Challenges (Brill Nijhoff, 2013); C. Aubertin and G. Filoche, 'The Nagoya Protocol on the Use of Genetic Resources: One Embodiment of an Endless Discussion', 2011 Sustentabilidade em Debate - Brasília 2(1), 51-64.

34 Latour 2005 supra n.1. 
researchers, local collaborators and the government of the host country that set the general lines of how the sharing of benefits emerging from the research collaboration should be organised. ${ }^{35}$ Benefit-sharing contracts are dependent on a number of assumptions and categorisations, in order to propose a model of distribution of values and resources. Here, they are interesting because they are dependent on a number of legal simplifications through categorisations that do not resist the test of everydayness, including the nature/society divide. ${ }^{36}$ This plays out at two levels: in relation to processes of valuing, and in relation to co-related processes of attribution and ownership.

ANT suggests that any object of study is complex in at least two respects: what it does, and what it embeds. The resources that bioprospecting contracts relate to are rich at both levels. They are hybrid resources that have become valued, used and enacted through their seizing and transformation across interactions and events, and they enter new processes of research and production that are always uncertain at the point of contract. The plants of bioprospecting are not bare objects, but materials that have become valuable through indigenous use, transformed again by their collection by bioprospectors, and may become yet something new if they participate in the making of an industrial product. Bioprospecting contracts, rather than entering a clearly categorised field in which they add an extra legal 'layer', become an inherent part of shaping what these plants are 'about', what type of value they hold, and in turn what sort of hybrid resource they constitute. In other words, bioprospecting contracts contribute to the production of the value of hybrid socio-natural objects. At the same time, benefit-sharing contracts are also embedded within a much larger political culture that continues to condition these productive processes by influencing the relative importance of various types of knowledges and resources. ${ }^{37,38}$

This raises methodological questions, in particular with regards to the different ways in which one may approach benefit-sharing processes, in order to render visible both the broader controversies on the interface between value and knowledge that they raise, and their practical translation. ANT's suggestion is that lending attention to the micro-workings of any particular object is the best way to bring out their political complexity,

35 Bhatti et al. supra n.33.

36 Latour 2012 supra n.1.

37 Itself entangled in the inherent postcoloniality of modern science (Whitt 2009 supra n.24; Harding 2011 and 2008 supra n.27).

38 Doris Schroeder and Thomas Pogge, 'Justice and the Convention on Biodiversity', 2009 Ethics and International Affairs 23(3), 267-282. 
and the translation of the broader patterns (or 'scripts') that they carry. Here, any decision on the relative fairness of different benefit-sharing arrangements is inevitably entangled in much broader processes of discursive recognition and empirical valuing, making it a necessarily difficult and deeply political process. ${ }^{39}$ To explore these entanglements, ANT suggests an empirical 'zooming-in', with a reflective attention to what else a particular object has become the materialisation of. For example, in observing closely the setting-up of agreements and the practical translation of notions of 'fairness', a researcher is also observing a microcosm of the much broader process of knowledge constitution. Instances of negotiations become both potential sites of resistance, by offering opportunities to indigenous parties to transform established meaning, and potential sites of dominance, by remaining located within broader patterns of exclusion and imbalance. ANT's emphasis on the need to break free from a 'structure/ agency' dichotomy offers possibilities to observe patterns and displacements within the localised itself.

Those who have paid close attention to the history of specific contracts emphasise further how the complexity of the resources those contracts are concerned with also results in complex movements around attribution and ownership. ${ }^{40}$ These hybrid resources are often spread across vast spaces, used by a variety of communities and groups, across national boundaries. Determining who participated in the shaping of a particular knowledge/ plant hybrid, both through space and time, is a complex process. As ANT reminds us, such processes are also always productive, or performative. Any practice of ordering, classification or identification, produces the identities it seeks to organise, rather than simply displacing pre-existing objects. Indeed, ethnographers of benefit-sharing contracts have emphasised this socially productive process. In bioprospecting missions, spaces of collection are almost always multiple: beside the classic imaginary of ethnobiologists collecting samples in wild rainforests, collections may happen in private estates, governmental gardens, on the edge of villages or in more remote areas, and, in many cases, in plant markets. ${ }^{41}$ These spaces are more than blank canvasses against which benefit-sharing conversations can take place. Instead, each of these spaces brings with it its own networked implications, complicating and diversifying further the nature of the conversations underway. As Cori Hayden reminds us:

39 For some of these broader conversation on knowledge-systems and valuing see for example S. Brush and D. Stabinsky, Valuing Local Knowledge: Indigenous People and Intellectual Property Rights (Washington: Island Press, 1996).

40 Hayden 2003b supra n.16; Osseo-Asare 2014 supra n.31.

41 Hayden 2003a supra n.16. 
For the ethnobotanists with whom I work, as for many of their colleagues in Mexico and elsewhere, the iconic twin images of plant-based drug discovery the intrepid explorer crashing through virgin jungle and the ethnobotanist as shaman's apprentice - fall far from the realities of everyday research. So does the vision of 'traditional knowledge' as an objectlike thing, fixed in place, isomorphic with easily identified and bounded communities. ${ }^{42}$

Paying attention to the role of materiality in those processes is also essential, and throughout stories of benefit-sharing contracts, the social role of materials pointed out by ANT is visible. Notably, the materiality of the object that is being collected, conditioned by the space in which the collection happens, may itself impact on processes of attribution. For example, plants displayed in markets or botanical gardens may carry explicit labelling of their associations to particular practices or users, and link in an uneasy way with the question of allocation, and of who is 'involved'. Hayden, in her investigation of Mexican researchers' interactions with such plants, points to a common tendency to consider markets as only intermediaries in the complex transmission of knowledge from imagined communities to individual researchers. ${ }^{43}$ She reminds us too, however, that this oversimplifies the performing mechanisms that transform resources as they are being shaped and prepared for market distribution, and the processes of exchange itself. This malleability of the spaces of bioprospecting, and of the consequent set of relationships that frame it, is a crucial aspect of the process, as search strategies, attribution, valuing, all become co-dependent, and influenced by broader processes and shifts. In turn, these micro-processes are highly political, both as embedding and generative of broader patterns of inclusion/exclusion. Legal tools become arbiters of the relative contribution of specific groups, producing new boundaries in any value-creation process. As they do so, they continue to carry the scripts of broader political patterns, as those that are less visible, governed in ways that are less facilitative of bioprospecting, whose knowledge falls most remotely into contemporary valuation processes, will remain excluded from what the law has put forward as a solution to ethical concerns. In this process, the possible tensions in the interests of scientific communities, governmental actors and local communities, $\mathrm{NGOs}^{44}$ and those they seek to protect or represent, may also be effaced in ways that reduce controversies to consensus.

42 Hayden 2003a supra n.16, p.363.

43 Hayden 2003a and b supra n.16.

44 Kristin Peterson, 'Benefit-Sharing for All: Bioprospecting NGOs, Intellectual Property Rights, New Governmentalities', 2001 Political and Legal Anthropology Review 24(1), 78-91. 


\section{4}

Apprehending these multiple shifts and complex processes as they are translated in practice raises important methodological insights. Notably, they remind us of the inherent limitations of any attempt at resolving complex hybrid choreographies through fixed legal frameworks, and in turn of the impossibility of fully apprehending the nature of legal objects, and legal solutions, without some attention to their practical workings. ${ }^{45}$ The modes of action of law are only fully visible if engaging with the material traces of benefit-sharing practice, but also more broadly with the social mechanisms that surround plant-use. The articulation of benefit-sharing into practice, and of the ethical questions at stake in individual decisions as suggested by law, is organised largely through the labelling of types of resources as 'indigenous', 'local' or 'national'. These labels have themselves emerged through the complex process of allocating relative contributions to the making of hybrid resources, and the origins of datasets collected through specific missions. Rather than the law being able to use such categories, or any other forms of ordering strategies, to simply address a pre-existing and independent context, such attempts are themselves both the product of significant social constructions, in which histories and politics are deeply entangled, and constitutive of the categories they propose. Resources that are labelled as 'traditional' have often a temporality that is more fluid than notions of tradition as 'past' and 'settled' may suggest; local resources are commonly dispersed; national resources are redefined through the constant political transformations of the private/public discursive split, of the redefinition of the links between particular territories and communities and governments; communities and market sellers are not necessarily dichotomic. For example, Hayden documents how ethnobotanical knowledge has been defined and redefined as traditional, indigenous or national in changing ways as the state of Mexico came to engage with bioprospecting contracts. ${ }^{46}$

This has implications for how we understand the modes of action of environmental law: rather than simply redistributing benefits and possibilities along pre-defined lines and categories, in the way the CBD and the Nagoya Protocol seem to suggest, benefit-sharing processes, and benefit-sharing contracts in particular, come to co-produce the situation they set out to regulate. As benefit-sharing contracts seek to organise themselves along the categorisations proposed by the law, and needed for it to function, they also come

45 Emilie Cloatre, 'Shifting Labels and the Fluidity of the "Legal"', in D. Cowan and D. Wincott (eds), Exploring the Legal in Socio-legal Studies (London: Palgrave Macmillan, 2016).

46 Hayden 2003b supra n.16. 
to settle new forms of relationships between actors, resources, space and time. More generally, the processes of medicinal production that surround the long history of traditional medicine demonstrate how such knowledge is produced across generations, spaces, borders and social boundaries, making it a hybrid mixture of experience, experiment, borrowing and inheriting. The complexity of allocation is here not only grounded in the multiplicity of the spatial configurations involved, but also in the difficulties of reconciling the particular temporality of the transmission of traditional medicine, and the expectation for the law that the transmission of knowledge can somehow be bounded in a particular moment, or temporality.

Overall, the logic of the law and that of the workings of collection and transmission in the practice of ethnobotany seem difficult to reconcile. Rather than a purely theoretical observation on the workings of law, this has deep implications for understanding both its practical potentialities and its practical effects. This suggests that a genuine engagement with the underlying ethics of bioprospecting, rather than seeking to 'fix' the specific issues at stake in the way new technological fixes may seek to patch climate change or other environmental threats, should attempt to critically evaluate the displacements and simplifications that those solutions suggest. Both the translation of knowledge as a matter of concern and the position of biodiversity as a nature/society hybrid are at stake here, as part of the broader political scripts the micro-practices concerned come to embed.

\section{SHIFTS AND DISPLACEMENTS: BENEFIT-SHARING AGREEMENTS AS SITES OF BROADER POLITICAL TENSIONS}

Benefit-sharing contracts, and benefit-sharing processes, are complex both because of the heterogeneity of each of the elements they distribute and create - beneficiaries, benefits, resources - but also because of the broader processes within which they are entangled. ${ }^{47}$ Therefore, any conversation about knowledge/value, about contributions, about the nature of useful products or the boundaries of what should be rewarded (and how) are part of what benefit-sharing procedures seek to shape, and part of much broader conversations they cannot be fully dissociated from, including debates in intellectual property.

Indeed, the relationship between value and knowledge that is fostered

47 Law 1986 supra n.2; Latour 2005 supra n.1. 
on the ground by benefit-sharing contracts is inherently conditioned by broader allocations of knowledge/power to particular sets of actors and debates on the position of nature within social networks. The ethnographic unpacking of the relationship between these political questions and everyday working of benefit-sharing agreements has demonstrated why some of these issues need to be engaged by environmental lawyers if environmental law is to offer more than limited and fixed answers to deep-running ethical issues. ${ }^{48}$ The logic of intellectual property law is based on the idea that rewards and incentives are important to generate and enhance particular forms of knowledge and particular forms of related activities, deemed to be of social value. ${ }^{49}$ Patents in particular are also primarily designed to reward work and knowledge-contributions that are geared towards industrial application, that can be bracketed off in time - with prior knowledge and new contributions clearly identifiable - and that can be allocated to a particular individual or identifiable entity. As is well known, and obvious from the above, this means that the forms of contributions that are involved in bioprospecting from provider spaces diverge considerably from this model.$^{50}$ In a context where the boundaries between natural resources and knowledge are unclear, where temporal limitations between what has been known, what has been adapted and what may be new forms of localised knowledge repackaged as traditions, are constantly moving, where identifying the specific contribution of individuals or groups to knowledge processes is impossible, the very logic of IP becomes problematic - yet persists in law, and in the research processes involved. ${ }^{51}$ In turn, possibilities for the shaping of benefit-sharing contracts, and of micro-resistance to dominant framings of natural resources or their loaded values, remain constrained by the dominant system of valuing and rewarding. ${ }^{52,53}$

48 Hayden 2003b supra n.16; Osseo-Asare 2014 supra n.31.

49 Graham Dutfield, Intellectual Property Rights, Trade and Biodiversity (London: Earthscan, 2000); Graham Dutfield, 'Sharing the Benefits of Biodiversity: Is There a Role for the Patent System?' 2002 Journal of World Intellectual Property 5(6), 899-931.

${ }_{50}$ Daniel A. Posey and Graham Duttfield, Beyond Intellectual Property: Towards Traditional Resource Rights for Indigenous People and Local Communities (Ottawa: International Development Research Centre, 1996).

${ }_{51}$ For an example of a well-known controversy see: E. Marden, 'The Neem Tree Patent: International Conflict over the Commodification of Life', 1999 Boston College International and Comparative Law Review 22, 279-298.

52 Coombe 2005 supra n.20.

53 On controversy-making from an STS perspective see Michel Callon, Pierre Lascoumes and Yannick Barthe Acting in an Uncertain World: An Essay on 
Focusing again on the methodological questions at stake, however, these various shifts can only fully be seized by a dual movement of attention to local translations and practices, and reflective engagement with broader notions of valuing as they transpire from the micro-level. This dual movement is challenging for the researcher, whose gaze needs to be equally directed at micro-interactions and the broader discourses they nudge towards. The added emphasis of ANT on the productive nature of any interactions, and in this case of those of legal objects with what they seek to regulate, adds yet more to those methodological challenges. The field is inevitably shifting, and what is at stake are moving objects that are always contingent on their interaction with others, and with the law. The process of understanding the law, in turn, is not about understanding the setting of rules to be applied to fixed objects, but instead is concerned with understanding its transformative effects on the very objects it sets out to regulate; the displacements of scripts and politics into new sites; and the rewriting of nature through everyday practices.

Observing those processes closely, at the same time, indicates something of the broader power patterns that (though also always susceptible to change) constrain localised movements. For example, the deep entanglement of patterns of power imbalance within the IP system come in turn to be embedded in and characterise the various agreements and materials that flow from it. The underlying assumptions of the mechanisms used for valuing knowledge, co-constituted through the dominant IP system, persist even in the localised sites that seek to engage with their limitations. As benefit-sharing agreements operate, they remain bound by broader networks that impact on the determination of values, and the determination of contributions as bounded in time and space. ${ }^{54}$ The mechanics of exclusion and sidelining that are inherent to such a bounded system of rights allocation are inevitably reproduced as categories are drawn to enable two competing forms of knowledge-systems and worldly logics to compromise. In these conversations, modernity cannot be reimagined to an extent that enables either the causes of discontent, or its effects, to be addressed in any straightforward way. ${ }^{55}$ The mechanisms at stake here participate in re-stabilising within entities a set of concepts that pre-existed elsewhere, and become reinforced as they acquired a

\footnotetext{
Technical Democracy (Cambridge, MA: MIT Press, 2010).

54 Coombe 1998 and 2005 supra n.20.

55 S.B. Banerjee, 'Who Sustains Whose Development? Sustainable Development and the Reinvention of Nature', 2003 Organization Studies 24(1), 143-180.
} 
new materiality. ${ }^{56}$ The potentiality for localised tools to participate in the transformation of the broader movements exists, but remains conditioned by their ability to engage, enrol and resist, which in the case of benefit-sharing agreements is still complicated by the uncertainty of the categories on which they formally rest, but of which they are also productive. ${ }^{57}$ The material responses that are deployed by environmental law in seeking solutions to biopiracy carry both the weight and script of broader tensions and contestations that surround valuing processes themselves; they also remain undetermined objects that are more easily drawn into the strong pre-existing networks of IP and industrial production than in the less established and less certain networks of the various communities, various histories, various interests and various knowledge techniques that differ from the predominant model. ${ }^{58}$ In order to draw out these interactions, researchers need to be able to deploy both an astute knowledge of the global politics at play, and of the everyday practices that surround bioprospecting. For ANT, this needs to be done through a methodological movement that combines ethnographic engagement with localised practices, and a conceptual reflection on their inscription in complex movements. These movements, however, rather than being structurally imposed on the local, are co-generated, and perpetuated (or at times challenged) by micro-interactions.

\section{ETHNOGRAPHY AND CRITIQUE: FROM EMPIRICAL UNPACKING TO CONCEPTUAL INTERROGATION}

The above analysis raises methodological questions that run beyond the example of bioprospecting. In particular, the question of how to relate micro-analysis and broader patterns opens challenging conceptual and practical questions, linked to some of the possibilities of both ANT and ethnography for critique. The emphasis of ANT on multiplicity,

56 Marilyn Strathern 'Potential Property: Intellectual Rights and Property in Persons', in Marilyn Strathern (ed), Property, Substance, Effect: Anthropological Essays on Persons and Things (London: Athlone Press, 1999, pp. 161-178).

57 E.B. Rodrigues, 'Property Rights, Biological Resources and Two Tragedies: Some Lessons from Brazil', in T. Bubela and E.R. Gold (eds), Genetic Resources and Traditional Knowledge (Cheltenham: Edward Elgar, 2012).

58 C. Oguamanam, 'Local Knowledge as Trapped Knowledge: Intellectual Property, Culture, Power and Politics', 2008 Journal of World Intellectual Property 11(1), 29-57. 
complexity and fluidity suggests that attention to the micro-details of this messiness are essential to any conceptualisation of the 'social'. At the same time, this attention to the micro and to fluidity rather than set patterns, has been at the core of some of the attacks made by those who deny the potential of ANT as a 'critical' methodology. In particular, one of the claims of ANT, and a consequence of ANT's emphasis on microinteractions, has been to challenge the usefulness of explanatory concepts to interpret the specific movements that may animate particular networks or objects. ${ }^{59}$ This means that ANT scholarship, in particular in its earliest or most mainstream version, has avoided engaging with key notions such as postcolonialism or neoliberalism to explain complex localised phenomena. In turn, this has attracted criticisms from those who have reminded us of the import of such historical patterns to understanding the processes of power that underlie social relations. ${ }^{60}$ However, a critical reading of ANT remains possible, if we accept that the emphasis on the instability of the social is compatible with the examination of persisting patterns: arguably, ANT does not seek to deny the processes others capture through terms such as capitalism, power, or the economy, but instead suggest that those are what needs to be explained through objectcentred analysis, rather than being explanatory tools in and of themselves. Recent literature in STS has in fact illustrated how the emphasis of the discipline on heterogeneity, fluidity and entanglement, could effectively be used to provide rich empirical critiques of persisting social patterns. ${ }^{61}$ Indeed, benefit-sharing agreements are a good example of how some of these patterns become displaced within the very solutions that are supposed to address them - while new solutions are being designed to ensure that those who have participated in developing a valuable form of knowledge receive a share of the benefits from those who wish to use this knowledge, the questions of who contributed, to what extent and where remain themselves open to a negotiation that can function, but only when specific circumstances mean that interests are balanced in an unusual way. ${ }^{62}$ In most cases, previous patterns of dominance continue to condition the negotiation of new legal arrangements. In practice, the form of

\footnotetext{
59 Bruno Latour, The Pasteurization of France (Cambridge, MA: Harvard University Press, 1993).

$60 \quad$ Harding 2008 and 2011 supra n.27; Anderson 2015, supra n.27.

61 E.g. Stacey Langwick, Bodies, Politics, and African Healing: The Matter of Maladies in Tanzania (Bloomington: Indiana University Press, 2011); Osseo-Assare 2014, supra n.31; Kristin Peterson, Speculative Markets: Drug Circuits and Derivative Lives in Nigeria (Durham: Duke University Press, 2013).

62 Osseo-Assare 2014 supra n.31.
} 
both modern capitalism and postcolonial relationships become slightly transformed, but also perpetuated. ANT and close-lens ethnographies are important tools not for the denial of these patterns, but for exploring the mechanics of their perseverance, and of their displacement in new loci.

However, much of this conversation goes beyond the specificities of ANT, and echoes important debates taking place amongst anthropologists interested in exploring the relationships between ethnography and critique. ${ }^{63}$ Here, the question is whether acknowledging and engaging with the messiness of the social, and of social research, leaves any possibility for theorising patterns and persisting movements. If we agree that the world is made of what some refer to as 'splinters' ${ }^{64}$ ' ${ }^{6}{ }^{2}{ }^{\prime}{ }^{65}$ or 'frictions', ${ }^{66}$ then a key task of scholarly research becomes to acknowledge the multiplicity of unexpected existences, events and transformation that any phenomena will encounter. This both makes the possibility of theorizing and some of the generalised claims that come with it problematic, and makes the need for rich case studies and descriptions particularly salient. Bielh and Locke, taking this difficulty on explicitly, remind us of the crucial role of ethnography for critique: 'In their relentless drive to theorise, anthropologists run the danger of caricaturing complex realities, neglecting key realms of experience, and missing lived ironies and singularities that might complicate and enrich analytics' ${ }^{67}$ Biehl and McKay make similar arguments, by exploring how recent scholarship seeks to unpack the 'splinters' of the global. They argue that critical ethnography is essential to understanding the messiness, pervasiveness and multi-layered movements of neoliberalism, of colonial history and of material terrains ${ }^{68}$ Here, the emphasis is on a mutual dependency of theory and empirical data, not dissimilar to ANT's attention to the interdependency of micro-movements and broader patterns.

The inherent importance of this dual movement of thinking about patterns while revisiting them by reasserting their ever-changing empirical complexity, is particularly acute when observing phenomena such as environmental law. Indeed, the significant global movements that animate this field, the diversity of cultural and social elements that test the bounda-

\footnotetext{
${ }^{63}$ Joao Biehl and Ramah McKay, 'Ethnography as Political Critique', 2012 Anthropological Quarterly 85(4), 1211-1230.

64 Anna Tsing 2005 supra n.13.

65 Law 2004 supra n.2.

66 Tsing 2005, supra n.13.

67 Joao Biehl and Peter Locke, 'Deleuze and the Anthropology of Becoming', 2010 Current Anthropology 51(3), 317-351.

68 Biehl and McKay 2012 supra n.63.
} 
ries and possibilities of environmental law, the tensions between conflicting interests, neoliberal pressures and persistent voices seeking to resist them, suggest that environmental law is a terrain that can particularly benefit from conceptually rich ethnographic explorations of its making and unmaking, supported by methodological tools that pay attention to materials in the way ANT does. At the same time, environmental law as a field seems to have resisted much of these conceptual and methodological movements so far. While empirical case studies have increasingly answered the limitations of a still predominantly doctrinal field, these have not always engaged in depth with any of the conceptual assumptions that the system is resting on, nor have they yet fully sought to reflect on what the messiness of the world suggests for the interface between empirical examples and conceptual engagement. ${ }^{69}$ Finally, ethnographic studies per se remain relatively limited in the field, and somehow sidelined, in a way that has limited the depth of critical engagement. Hirshmann's call for 'a little more reverence for life, a little less straitjacketing of the future, a little more allowance for the unexpected - and a little less wishful thinking ${ }^{70}$ seems to apply here as well as it does in many other fields. Indeed, the example provided below explores the type of questions, and the type of analyses, that would go amiss in the field if others were not, in other disciplines, interrogating law in a way that environmental lawyers have not often done - indeed replicating time after time some of the limitations of the legal system itself.

\section{CONCLUSIONS}

ANT, as characterised through this analysis, constitutes a toolbox that offers important conceptual and methodological resources for researchers, but also generates a number of challenges. Its constant emphasis on the entanglement and interdependency of actors and processes, on the fluid nature of the social, on the productive and multidirectional effects of the deployment of any actor, suggests a messy vision of the object of analysis.

${ }^{69}$ For a related critique see E. Fisher, B. Lange and E. Scotford, 'Maturity and Methodology: Reflecting on How to Do Environmental Law Scholarship' 2009 Journal of Environmental Law 1; see also A. Kotsakis, 'Change and Subjectivity in International Environmental Law: The Micro-Politics of the Transformation of Biodiversity into Genetic Gold', 2014 Transnational Environmental Law 3(1), 127-147.

70 Albert Hirschman, Crossing Boundaries: Selected Writings (New York: Zone Books, 1998, p. 338) (as quoted in Biehl and McKay supra n.63). 
Through this chapter, however, I hope to have demonstrated that it also potentially enables such a vision to be rich and fruitful. However, this also necessitates the deployment of methods that are apt to the seizing of messiness, and of micro-interactions. Explorations of how the law works in practice, of what it transforms, of the new forms of ordering it creates, and the new identities it produces as a result, necessitate an attention to micro-details that is best provided by in-depth ethnographic techniques. This attention to localised movements does not replace an interrogation of broader political patterns, but helps in forming a better understanding of their making, perpetuating, and dislocations, than doctrinal methods, for example, would allow.

The role of environmental law itself, through this lens, becomes multiple. Here for example, on the one hand, it set out to respond to a particular set of debates. But, on the other, arguably, doing so results in it participating in a more complex co-production and mutual reshaping of identities and nature. ${ }^{71,72}$ ANT helps pay attention to these productive processes, while remaining alert to their interrelationship with deeper frictions, discontents and tensions between conflicting political visions of the position of nature, as well as the competing knowledge-systems it is entangled with. It suggests, however, that this is best grounded in a distinct attention to material practices - such as, here, benefit-sharing contracts and their making - not as fixed or stable moments, but as complex processes of constitution. The image of law that emerges is not necessarily consistent with what the legal system may project, but seeks to focus on law as it is translated and experienced. Bioprospecting as a messy problem will inevitably respond in messy ways to any attempt to order the field, and while environmental law as a technique of governance may seek to develop processes for ordering, environmental law scholars need to pay attention to the significance of discrepancies in its translation, and to the limits of its discursive propositions when put to the test of social messiness. In the way that any division between nature and society appears as increasingly fragile when it is interrogated, and in the way that most categorisation proposed by law to address a problem as complex as that of bioprospecting becomes unhelpful once unpacked, any imaginary of law as being potentially external to the problems it seeks to regulate seems to run counter to the more complex landscape of benefit-sharing

${ }_{71}$ Hayden 2003b supra n.16.

72 B. Parry, "Hunting the Gene-hunters: The Role of Hybrid Networks, Status, and Chance in Conceptualising and Accessing "Corporate Elites", 1998 Environment and Planning A 30(12), 2147-2162. 
Actor-network theory and the empirical critique of environmental law 103 mechanisms. Here, nature, cultures, identity, modernity and politics are interlinked in the constantly shifting terrains of negotiations over resource-hybrids, competing knowledge-systems and the relative values, spatiality and temporal distributions of each. 